\title{
Renal Fanconi syndrome in distal renal tubular acidosis
}

\author{
Toru Watanabe ${ }^{1}$
}

Received: 28 February 2017 / Accepted: 2 March 2017 / Published online: 15 March 2017

(C) IPNA 2017

Dear Editor,

I read with great interest the article in your journal by Besouw et al. titled "Clinical and molecular aspects of distal renal tubular acidosis in children" [1]. The authors reported that 16 of 24 patients with distal renal tubular acidosis (dRTA) showed transient and partial renal Fanconi syndrome that resembled Dent disease or Lowe syndrome. This finding suggested that renal Fanconi syndrome in dRTA may be due to impairment of similar pathways in both diseases. Molecular analysis of vacuolar $\mathrm{H}^{+}$-ATPase (V-ATP) in their dRTA patients with renal Fanconi syndrome showed nine had the ATP6V0A4 mutation, three the ATPV1B1 mutation, and four had no apparent gene mutation.

Renal proximal tubular dysfunction in untreated patients with dRTA has also been reported previously [1, 2]. Although the precise pathogenic mechanism underlying development of this condition remains unclear, it has been suggested that hypokalemic nephropathy and defective V-ATPase resulting in impaired endosomal acidification may be involved [1, 2]. However, because the B1 subunit of VATPase is not expressed in renal proximal tubular cells, defective V-ATPase is unlikely to cause renal proximal tubular dysfunction in dRTA patients with the ATPVIB1 mutation [2].

Expression of CLC-5 $\left(2 \mathrm{Cl}^{-} / \mathrm{H}^{+}\right.$exchanger $)$in apical endosomes of renal proximal tubules containing V-ATPase acts functionally in the normal endosomal pathway coupling with V-ATPase. In contrast, genetic mutations of CLC-5 cause Dent disease [3]. Recent studies demonstrated that low extracellular $\mathrm{pH}$ or acidosis inhibits CLC-5 function that occurs as a consequence of a reduction in the driving force for exchange caused by the $\mathrm{pH}$ gradient [4]. Inhibition of CLC-5 function due to systemic acidosis may lead to renal proximal tubular dysfunction in pretreated patients with dRTA.

\section{Compliance with ethical standards}

Conflict of interest The author declares no conflict of interest

\section{References}

1. Besouw MT, Bienias M, Walsh P, Kleta R, Van't Hoff WG, Ashton E, Jenkins L, Bockenhauer D (2017) Clinical and molecular aspects of distal renal tubular acidosis in children. Pediatr Nephrol. doi:10.1007/ s00467-016-3573-4 (erratum doi:10.1007/s00467-017-3631-6)

2. Tasic V, Korneti P, Gucev Z, Hoppe B, Blau N, Cheong HI (2008) Atypical presentation of distal renal tubular acidosis in two siblings. Pediatr Nephrol 23:1177-1181

3. Satoh N, Suzuki M, Nakamura M, Suzuki A, Horita S, Seki G, Moriya K (2017) Functional coupling of V-ATPase and CLC-5. World J Nephrol 6:14-20

4. Picollo A, Malvezzi M, Accardi A (2010) Proton block of the CLC-5 $\mathrm{Cl}^{-} / \mathrm{H}^{+}$exchanger. J Gen Physiol 135:653-659

Toru Watanabe

twata@hosp.niigata.niigata.jp

1 Department of Pediatrics, Niigata City General Hospital, 463-7

Shumoku, Chuo-ku, Niigata City 950-1197, Japan 